\title{
Development and Validation of a New Scale to Assess Attitudes and Perspectives Toward Persons With Disabilities
}

\author{
Youho Myong, MD ${ }^{1}$, Hyung-Ik Shin, MD, PhD ${ }^{1}$, Jeong-Eun Lee, $\mathrm{PhD}^{2}$, \\ Woosup Cho, $\mathrm{MD}^{1}$, You Gyoung Yi, $\mathrm{MD}, \mathrm{PhD}^{1,3}$
}

\begin{abstract}
${ }^{1}$ Department of Rehabilitation Medicine, Seoul National University Hospital, Seoul National University College of Medicine, Seoul; ${ }^{2}$ Biomedical Research Institute, Seoul National University Hospital, Seoul;

${ }^{3}$ National Traffic Injury Rehabilitation Hospital, Yangpyeong, Korea
\end{abstract}

Objective To develop and validate a scale to assess people's attitudes and perspectives toward persons with disabilities.

Methods The three-stage development of the scale included a preliminary version drafted from the literature review and a nominal group process. Thereafter, the draft was examined further and revised through two rounds of Delphi survey by 16 disability experts. Lastly, the psychometric properties of the scale were assessed through an online survey of 1,359 employees at three university hospitals.

Results A 32-item scale, defined after two Delphi surveys, was refined into 14 items with four subcategories: community integration, discomfort, charitability, and sense of burdening. The Cronbach's alpha coefficient was 0.839 and domain reliability from 0.638 to 0.845 . Recent education on disabilities yielded more positive attitudes toward persons with disabilities. Meaningful acquaintances with disabilities yielded more positive attitudes toward persons with disabilities.

Conclusion This newly developed scale that measures attitudes toward persons with disability is reliable and valid. A future use of the scale could be to measure attitudinal improvements toward persons with disabilities after awareness education.

Keywords Attitude, Persons with disabilities, Psychometrics

Received March 4, 2021; Revised April 29, 2021; Accepted July 1, 2021; Published online August 30, 2021

Corresponding author: You Gyoung Yi

Department of Rehabilitation Medicine, Seoul National University Hospital, Seoul National University College of Medicine, 101 Daehak-ro, Jongno-gu, Seoul 03080, Korea. Tel: +82-31-580-5548, Fax: +82-31-580-5785, E-mail: lyk861124@gmail.com

ORCID: Youho Myong (https://orcid.org/0000-0002-2469-839X); Hyung-Ik Shin (https://orcid.org/0000-0001-8805-3104); Jeong-Eun Lee (https:// orcid.org/0000-0001-6104-3168); Woosup Cho (https://orcid.org/0000-0003-3517-138X); You Gyoung Yi (https://orcid.org/0000-0003-1791-1831).

(c) This is an open-access article distributed under the terms of the Creative Commons Attribution Non-Commercial License (http://creativecommons.org/ licenses/by-nc/4.0) which permits unrestricted noncommercial use, distribution, and reproduction in any medium, provided the original work is properly cited. Copyright ( 2021 by Korean Academy of Rehabilitation Medicine 


\section{INTRODUCTION}

Attitude is the feeling or disposition of a person acquired through experience [1-3]. Negative attitudes toward persons with disabilities (PWD) are prevalent across diverse cultures [4]. Such attitudinal barriers can bar PWD from social inclusion, such as receiving equal opportunities for employment, education, and social services.

Developing and validating a scale to measure attitudes is important because it allows one not only to measure the cross-sectional attitude of a specific population toward PWD but also to examine the changes in its attitudes before and after appropriate intervention, such as disability awareness education. Various scales have been developed to measure attitudes toward PWD $[5,6]$. These scales, such as the Disability Factor Scales (DFS) [7], Attitudes Toward Disabled Persons Scale (ATDP) [8], and the Scale of Attitudes Toward Disabled Persons (SADP) [9] are widely used in researching the attitudes of general or specific populations, such as healthcare workers. Some of these scales have received criticism that some of their items were preferred by extreme scores, and thus they lack proper discrimination power because the respondents are more likely to answer in a way that is socially desirable [9]. Yet other scales specify a type of disability or address a particular population, thus limiting their

Table 1. Demographic characteristics of the respondents

\begin{tabular}{lccc}
\hline & $\begin{array}{c}\text { Group 1 } \\
(\mathbf{n = 6 8 0})\end{array}$ & $\begin{array}{c}\text { Group 2 } \\
(\mathbf{n = 6 7 9 )}\end{array}$ & $\begin{array}{c}\text { Total } \\
(\mathbf{n = 1 , 3 5 9 )}\end{array}$ \\
\hline Age (yr) & $36.4 \pm 9.0$ & $36.9 \pm 9.4$ & $36.6 \pm 9.2$ \\
Sex & & & \\
$\quad$ Female & $444(69.38)$ & $434(69.77)$ & $878(69.57)$ \\
$\quad$ Male & $196(30.63)$ & $188(30.23)$ & $384(30.43)$ \\
Occupation & & & \\
$\quad$ Medical & $142(20.88)$ & $110(16.20)$ & $252(18.54)$ \\
Nursing & $249(36.62)$ & $271(39.91)$ & $520(38.26)$ \\
Other healthcare & $113(16.62)$ & $108(15.91)$ & $221(16.26)$ \\
\hline Administrative & $176(25.88)$ & $190(27.98)$ & $366(26.93)$ \\
Years of service & $8.9 \pm 8.9$ & $9.4 \pm 9.2$ & $9.2 \pm 9.1$ \\
\hline
\end{tabular}

Values are presented as mean \pm standard deviation or number (\%).

Participants were randomly assigned to group 1 and group 2. Exploratory factor analysis was performed in group 1 ; confirmatory factor analysis, in group 2. scalability to all types of disabilities or to the public (Table 1).

The ATDP-Form O (ATDP-O), a scale widely used to measure societal attitudes toward PWD, was developed in 1960. Concerns have been expressed that the ATDP is outmoded and may no longer adequately reflect current societal views. Studies have found that the ATDP may be susceptible to socially desirable responses. Yuker and Block [10], the developers of the scale reported that, "the studies to date indicate that ATDP scores can be distorted," and suggested that ATDP can be used as part of a "battery of measures."

The SADP, developed by Antonak [9] in 1981, is another widely employed scale to measure attitudes toward PWD. Although extensively used, SADP includes a few items that may not be applicable to the present day. For example, responses to items such as, "People with disabilities should be prevented from having children," or "An individual with a disability is not capable of making moral decisions," may show little variation because respondents are likely to disagree with them homogeneously [11].

A more recently developed instrument, the Multidimensional Attitude Scale Toward Persons with Disabilities (MAS), addresses attitudes toward PWD in multiple dimensions: affect, cognition, and behavior [12]. While MAS investigates the multidimensionality of attitudes, the scale specifies the type of disability (physical disability) and the situation (meeting an individual with a disability for the first time). Therefore, its relevance to other types of disability in various situations may be restricted.

Reliable and valid scales to measure social attitudes on PWD are important because not only can they be used to assess cross-sectional attitudes of the public, but also can be useful in tracking temporally serial development of attitudes. It has been reported that disability awareness education for the public can be helpful in promoting positive social attitudes on PWD [12]. Close interactions with PWD, such as having one as a close acquaintance, is also known to positively influence affective, cognitive, and behavioral attitudes on PWD. Therefore, it is important that an up-to-date, reliable, and valid scale be developed in order to check and track the cross-sectional and timeserial distribution of social attitudes on PWD.

As such, this paper aims to fulfill two main objectives. The primary objective of the study was to develop and validate a reliable scale to measure the social attitudes 
toward PWD: the Attitudes and Perspectives toward Persons with Disabilities (APPD). The secondary objective of the study was to examine the different social attitudes on PWD across various groups of people. More specifically, we report the difference in attitudes on PWD among two pairs of groups: those with and without close acquaintances as PWD, and those with and without disability awareness education.

\section{MATERIALS AND METHODS}

The APPD was developed between April 2018 and September 2018.The authors conducted a systematic electronic search in PubMed, MEDLINE, Cochrane Library, Korean Research Information Sharing Service, Korean Studies Information Service System, and Korean National Assembly Library in April 2018. The preliminary search strategy was to use the following keywords: "disabled person," "scale," "attitudes," "persons with disability." The studies were selected independently by two authors and were included if the studies were (1) published in English or Korean, (2) concerns development, validation, revision, translation, or application of scales to measure various attitudes on PWD. Of the 1,957 initially collected studies, 23 scales regarding attitudes on PWD, such as ATDP-O, SADP, DFS, Interaction with Disabled Persons Scale (IDP), Contact with Disabled Persons Scale (CDP), Attitudes to Blindness Scale (AB), and the Opinions about Deaf People scale (ODP) were included.

Based on the items from the 23 scales, the authors first identified three domains of attitudes: affective, cognitive, and behavioral. Sixty preliminary questions were drafted for the three domains. The draft was refined through two rounds of Delphi survey, as described in the following section and Fig. 1. Thereafter, employees and volunteers of a university hospital in Seoul, South Korea were surveyed online to assess the psychometric properties of the scale. All procedures employed in the present study were concordant with the institutional and national research committee ethical standards and with the 1964 Helsinki Declaration. Ethical approval was obtained from the Institutional Review Board of Seoul National University Hospital (No. 1808-173-969). Written informed consent was collected for each participant.

\section{Development of the APPD scale}

Between April 22, 2018 and June 19, 2018, the authors conducted in-depth interviews with 25 PWD who were over 18 years old, community dwelling, and able to communicate with the interviewers. The qualitative interview focused on the interviewees' life experiences, such as experiences of being discriminated against or treated unfairly because of their disabilities, or prejudices and misunderstandings of the general population against PWD. Eleven (44.0\%) respondents were male and 14 (56.0\%) were female. The mean age was 38 years, with the youngest participant being 21 years and the oldest, 52 years. The proportions of the types of disabilities were as follows: physical disabilities (36.0\%), visual impairment (32.0\%), hearing impairment (16.0\%), and intellectual disabilities (16.0\%). Three of the interviewees (12.0\%) had graduate degrees, $12(48.0 \%)$ had college degrees, and $10(40.0 \%)$ had high school diplomas or less than twelve years of education. Thirteen $(52.0 \%)$ were paid workers, five $(20.0 \%)$ were self-employed, five $(20.0 \%)$ were unemployed, and two $(8.0 \%)$ were students. After a literature review and in-depth interviews, a preliminary script of APPD was constructed. The items were then refined through two rounds of Delphi survey.

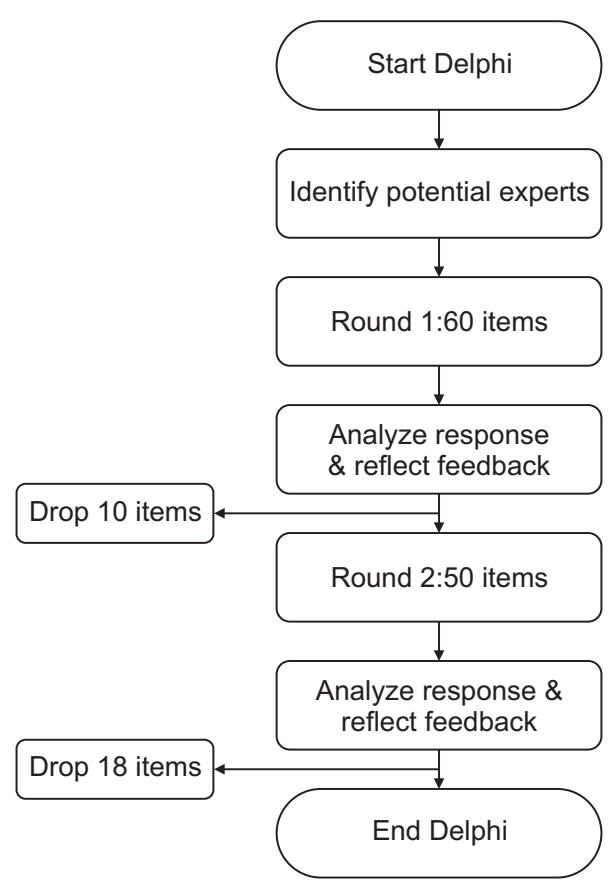

Fig. 1. Delphi survey process. 


\section{Delphi survey: Round 1}

The expert group included six healthcare professionals, six PWD welfare specialists, and four human rights activists mainly working for PWD. In both rounds of Delphi survey, expert group gathered to study and discuss the preliminary draft of APPD to yield both quantitative and open-ended feedback. Participants studied each item and responded to open-ended questions by giving opinions and to questions with a 5 -point Likert scale ( $1=$ not adequate, $2=$ somewhat adequate, $3=$ neutral, $4=$ quite adequate, and $5=$ highly adequate). The responses were averaged excluding the highest and lowest values. Items with a point average lower than 4.00 were excluded from the preliminary draft. Exceptions were made for items if they had reasonable theoretical support in constituting a valid viewpoint or if there were significant differences in point averages across specific field of expertise. The revision reflected the expert commentary; items that were similar were merged or deleted, and items that were ambiguous were rephrased for clarity. The first round excluded 10 items, leaving 50 questions for the second round of Delphi survey.

\section{Delphi survey: Round 2}

In the second round of Delphi survey, the expert panel again gathered to review the group scores and their own scores for each item and re-rate the 50 remaining items using the same 5-point Likert scale. The same exclusion criteria were used as in the first round, leaving 32 items for the initial survey and the psychometric property assessment. The open-ended expert commentary from the second round was reflected in the final draft before survey. The entire process of Delphi survey is presented in Fig. 1.

\section{Psychometric property assessment}

We used SurveyMonkey (https://ko.surveymonkey. $\mathrm{com} /$ ), an online survey software, to conduct and analyze our survey. Employees of three university hospitals, such as social workers, administrative staff, security staff, and volunteers, were invited to the online survey via email. The online survey was conducted for 2 weeks, from September 18 to 25,2018 . The survey included 32 items of the APPD, demographic data, professional knowledge regarding each type of disability, and whether the respondent had previously participated in disability awareness education. The respondents were also surveyed for family members or meaningful acquaintances with disabilities.

\section{Data analysis}

A standard composite score method was used for the preliminary draft. The draft was composed of 5-point Likert scale items; responses for the negatively worded items were inverted so that a higher score reflects a more positive attitude. Before the factor structure was identified within the scale, item analysis was conducted through item-total correlation and communality index. The item-total correlation check is performed to determine whether responses to a specific item align with responses to other items within the scale. The item being tested is dropped if its responses are not consistent enough with the averaged responses of other items. The cutoff value of the item-correlation check was 0.2 . The communality index measures how well an item correlates with all other times; therefore, higher communality indicates a more rigorous correlation among the items within a scale. The communality index was considered appropriate if it was 0.4 or greater.

The sample of the respondents was divided randomly into two groups in an approximately 1:1 ratio using SAS 9.3 (SAS Institute Inc., Cary, NC, USA). Exploratory factor analysis was conducted in the first group and confirmatory factor analysis was conducted in the second. Principal axis factoring was used as the estimation method and direct oblimin was used as the rotation method in the exploratory factor analysis. A factor loading of 0.4 or greater was considered sufficient.

In the confirmatory factor analysis, maximum likelihood was used as the estimation method and geomin (oblique) rotation was used as the rotation method. To determine the model fit, the Tucker-Lewis Index (TLI), the Comparative Fit Index (CFI), and the root mean square error of approximation (RMSEA) were calculated. The model was considered adequate if the TLI and CFI were 0.9 or greater and if the RMSEA was 0.08 or less. We calculated the internal consistency using the Cronbach's alpha coefficient.

ANOVA and independent t-tests were used to identify any significant difference in attitude toward PWD according to whether they had a family member or meaningful acquaintances with disabilities, or whether they had previously participated in disability awareness education. 


\section{RESULTS}

\section{Development of the APPD scale}

A preliminary literature research with the keywords, "disabled person," "scale," "persons with disability," and "attitude," found 16 widely recognized attitudes toward PWD scales, including ATDP-O [8], SADP [9], DFS [7], and IDP [11] (Supplementary Table S1). Additionally, we included attitude scales for specific types of disability, such as $A B$ [13] and the ODP [14]. The in-depth interviews provided further proof of the negative experiences of PWD from the general population. These experiences included expected inferiority ("PWD are dependent," "PWD contribute less to the community," "PWD achieve less due to their disability"); unwarranted sympathy ("PWD need social protection," "PWD deserve limited freedom for their own safety"); higher social bars ("PWD must work harder to 'overcome' their disability," "PWD must try harder not to fall behind their colleagues without disabilities," "PWD must inspire those around them"); expected gratitude ("PWD must accept and be grateful for any help from those without disability"); prejudice ("PWD are difficult to cope with," "any mistakes or failures experienced by PWD are due to their disability," "PWD use their disability as an opportunistic excuse"); and reverse discrimination ("PWD are getting disproportionate amounts of social and financial support," "PWD always want more support, regardless of their current socioeconomic status").

We initially developed 60 items for the attitude scale based on the literature review, consensus meeting, and the in-depth interviews. Based on the multicomponent model by Eagly and Chaiken [15], the initial 60 items were categorized into three main domains: cognitive, affective, and behavioral. The preliminary scale was then sent to 16 experts (six healthcare professionals, six PWD welfare specialists, and four human rights activists working mainly for PWD) for two rounds of Delphi survey. After a thorough process of amendment and revision, the Delphi rounds culminated in 32 items on a 5-point Likert-type scale instrument, of which more than $80 \%$ of the experts approved.

\section{Psychometric properties of the attitude toward PWD}

A total of 1,359 employees from three university hospitals completed the online survey. By using SAS, the sample was randomly divided into two groups: group 1 for item analysis and exploratory factor analysis and group 2 for confirmatory factor analysis (Table 1). Item analysis was performed in the first group $(n=680)$. Three items (items \#6, \#20, and \#25) had an item-total correlation less than 0.2. Four items (items \#6, \#17, \#20, and \#25) had a communality index of less than 0.3 . Items 27 and 28 had an item-for-item correlation of 0.8874 . Therefore, five items (items \#6, \#17, \#20, \#25, and \#28) were excluded, leaving 27 items for exploratory factor analysis (Supplementary Table S2).

To investigate the number of factors among these items, an exploratory factor analysis was conducted. Principal axis factoring was used as the main estimation method, and direct oblimin was used as the rotation method. Items with factor loadings of less than 0.4 was determined not to belong to any factor. Thirteen items (items $\# 3$, \#7, \#9, \#12, \#13, \#14, \#21, \#24, \#27, \#29, \#30, \#31, and \#32) were removed, leaving 14 items which originally belonged to three domains: cognitive, affective, and behavioral. The eigenvalues with corresponding variance are presented in Table 2 . The accumulated variance suggested the optimal number of factors as three or four.

Compared to the three-factor model that explains less than half of the total variance of the responses, the fourfactor model explained additional variance of 5.135\%, covering majority of the total variance $(52.061 \%)$. In addition to the ability to explain much of the variance, the four-factor model distinguishes items that later become the subcategory of sense of burdening from those that later become the subcategory of discomfort. The two subcategories, although stemming from the same Atkinsonian viewpoint of social burden, are inherently different in that the discomfort subcategory focuses more on the personal affective response of the respondent, while the

Table 2. Eigenvalues and cumulative variance explained by number of factors

\begin{tabular}{lccc}
\hline \multicolumn{1}{c}{ Model } & Eigenvalue & $\begin{array}{c}\text { Additional } \\
\text { variance (\%) }\end{array}$ & $\begin{array}{c}\text { Cumulative } \\
\text { variance (\%) }\end{array}$ \\
\hline Single-factor & 7.034 & 30.585 & 30.585 \\
Dual-factor & 2.365 & 10.281 & 40.865 \\
Three factor & 1.394 & 6.061 & 46.926 \\
Four factor & 1.181 & 5.135 & 52.061 \\
Five factor & 1.095 & 4.760 & 56.822 \\
Six factor & 0.999 & 4.345 & 61.167 \\
\hline
\end{tabular}


sense of burdening subcategory inquires if the respondent agrees with the objective statement that the PWD as a population burdens the society. The content, item-total correlation, and structural coefficients of the instrument for the measurement of attitudes toward PWD with disabilities are shown in Table 3.

To test the model fit of the four-factor, fourteen-item scale, we conducted a confirmatory factor analysis using group $2(\mathrm{n}=579)$. The instrument showed a good fit with the data, with the following indices: $\chi^{2}=331.51, \mathrm{df}=71$, $\mathrm{p}<0.0001, \mathrm{CFI}=0.9123$, TLI $=0.8877$, RMSEA $=0.0753$. Since the RMSEA $<0.08$, and CFI $>0.9$, the model was in agree- ment with the data. The Cronbach's alpha coefficients of the categories ranged from 0.6376 to 0.8454 (Table 3 ).

Differences in attitudes according to whether family or significant acquaintances had disabilities

Of the 1,288 respondents, 385 (29.9\%) had meaningful acquaintances, such as family, friends, or colleagues, who had disabilities, and $910(70.1 \%)$ did not. The two groups showed significant differences in the total score of APPD with those who had meaningful acquaintances with disabilities exhibiting more positive attitudes toward PWD (Table 4). More specifically, the groups' attitudes

Table 3. Items of the attitude toward persons with disabilities scale, item-subdomain correlation, and internal consistency coefficients

\begin{tabular}{|c|c|c|c|c|}
\hline Item & $\begin{array}{l}\text { Community } \\
\text { integration }\end{array}$ & Discomfort & Charitability & $\begin{array}{c}\text { Sense of } \\
\text { burdening }\end{array}$ \\
\hline $\begin{array}{l}\text { Persons with disability should live with those without } \\
\text { disability in community. }{ }^{\text {a) }}\end{array}$ & 0.7419 & & & \\
\hline $\begin{array}{l}\text { If provided adequate support, persons with disability } \\
\text { can lead social lives as people without disability can. }{ }^{\text {a) }}\end{array}$ & 0.5200 & & & \\
\hline $\begin{array}{l}\text { Persons with disability deserve to live where they want } \\
\text { in ways they want. }\end{array}$ & 0.6815 & & & \\
\hline $\begin{array}{l}\text { With sufficient qualifications and through legitimate } \\
\text { process, persons with disability can be elected. }{ }^{\text {a) }}\end{array}$ & 0.7474 & & & \\
\hline $\begin{array}{l}\text { I will not let my children hang out with children with } \\
\text { disability. }\end{array}$ & 0.4539 & & & \\
\hline $\begin{array}{l}\text { I feel uncomfortable being around persons with disability } \\
\text { because I feel like I need to help them. }\end{array}$ & & 0.7151 & & \\
\hline $\begin{array}{l}\text { I feel uncomfortable encountering persons with disability } \\
\text { because I am not sure how to treat them. }\end{array}$ & & 0.8345 & & \\
\hline $\begin{array}{l}\text { It is difficult for me to approach persons with disability, } \\
\text { because I feel like they are different from me. }\end{array}$ & & 0.5683 & & \\
\hline $\begin{array}{l}\text { If I had a family member with disability, I would not want } \\
\text { people to find out. }\end{array}$ & & 0.4012 & & \\
\hline $\begin{array}{l}\text { Persons with disability would consider themselves } \\
\text { unfortunate. }\end{array}$ & & & 0.4783 & \\
\hline I feel bad for persons with disability. & & & 0.8949 & \\
\hline $\begin{array}{l}\text { I feel sorry for persons with disability when they need to put } \\
\text { extra effort to do daily tasks. }\end{array}$ & & & 0.6679 & \\
\hline $\begin{array}{l}\text { Persons with disability usually ask special treatment for their } \\
\text { disability. }\end{array}$ & & & & 0.8271 \\
\hline $\begin{array}{l}\text { Persons with disability tend to leave difficult tasks for people } \\
\text { without disability. }\end{array}$ & & & & 0.8202 \\
\hline $\begin{array}{l}\text { Internal consistency coefficients between subdomain score } \\
\text { and total Attitude and Perspectives toward Persons with } \\
\text { Disabilities Scale. }\end{array}$ & 0.7564 & 0.7848 & 0.6376 & 0.8454 \\
\hline
\end{tabular}

${ }^{a)}$ Reverse coded items. Higher scores indicate more negative attitudes toward disability. 
Table 4. Difference in attitudes based on having meaningful acquaintance with disability

\begin{tabular}{lccc}
\hline \multicolumn{1}{c}{ Subcategory } & Acquaintance with disability $(\mathbf{n = 3 7 8 )})$ & No acquaintance with disability $(\mathbf{n = 9 1 0 )}$ & $\mathbf{p}$-value \\
\hline Total score & 2.428 & 2.531 & $0.019^{*}$ \\
Community integration & 1.761 & 1.887 & $0.011^{*}$ \\
Discomfort & 2.428 & 2.638 & $0.007^{*}$ \\
Charitability & 3.083 & 3.083 & 0.498 \\
Sense of burdening & 2.442 & 2.515 & 0.115 \\
\hline
\end{tabular}

Higher scores indicate more negative attitudes toward disability.

${ }^{*} \mathrm{p}<0.05$.

Table 5. Difference in attitudes based on having recently participated in awareness education

\begin{tabular}{lccc}
\hline \multicolumn{1}{c}{ Subcategory } & Participation within 2 years $(\mathbf{n = 2 1 5})$ & No participation within 2 years $(\mathbf{n = 1 , 0 7 3 )}$ & $\mathbf{p}$-value \\
\hline Total score & 2.436 & 2.513 & $0.014^{*}$ \\
Community integration & 1.793 & 1.862 & $0.029^{*}$ \\
Discomfort & 2.477 & 2.595 & $0.009^{* *}$ \\
Charitability & 3.006 & 3.098 & $0.035^{*}$ \\
Sense of burdening & 2.467 & 2.499 & 0.300 \\
\hline
\end{tabular}

Higher scores indicate more negative attitudes toward disability.

${ }^{*} \mathrm{p}<0.05,{ }^{* *} \mathrm{p}<0.01$.

diverged in the subcategories of community integration and discomfort. There was no significant difference in attitudes regarding the charitability and sense of burdening subcategories.

\section{Differences in attitude according to participation in disability awareness education}

Of the respondents, 215 (16.7\%) have participated in organized disability awareness education modules within the past 2 years from the time of the survey, and 1,073 (83.3\%) had not. The employees who answered that they had recently participated in awareness education showed a significantly more positive overall attitude and "community integration," "discomfort," and "charitability" subdomain scores (Table 5). There was no statistically significant difference in the "sense of burdening" subdomain between the two groups.

A total of 678 (52.6\%) respondents answered that they had participated in disability awareness education modules at some time during their careers, regardless of how recent they were. A total of 610 (47.4\%) answered that they had no experience of participating in disability awareness education. Between these two groups, there were no significant differences in APPD scores as a total or in any individual subdomain.

\section{DISCUSSION}

In this study, we developed and validated the APPD, a 14-item scale that assesses attitudes toward PWD (Supplementary Table S3). Through factor analysis, we classified the 14 items in the APPD into four subcategories: community integration, discomfort, charitability, and sense of burdening. The APPD scale showed good internal consistency, model fit, and construct validity.

Many existing scales assessing attitudes toward PWD were developed targeting a specific population, such as medical students, healthcare professionals, social workers, or PWD or their guardians. Such instruments, like Social Workers' Attitudes Toward Disability Scale [5], Disability Attitude in Health Care [16], and Medical Students Attitudes Toward People with Disability [17], are recent and valid, but nonetheless have limitations when studying the general population.

The need for a more up-to-date instrument has been constantly proposed $[9,18]$. Nevertheless, relatively recent scales developed in the 1980s contain several items that may show little variation in responses, thus lacking the power of discrimination. For example, the SADP includes items such as, "the disabled should be committed to an institution following arrest," or that, "the disabled should 
be prevented from having children." Such statements will most likely homogenously be disagreed upon by modern respondents, thus diminishing the scale's value as a sensitive measurement tool.

More recently, Findler et al. [12] developed MAS in 2007. MAS is a 34-item scale that measures attitudes toward PWD in a tripartite view. In its original version, MAS comprises three subdomains: cognition, affect, and behavior. MAS provides a hypothetical situation where the respondent is left alone with a person in a wheelchair to whom an introduction has just been made. The respondent's affect, thoughts, and possible behavior in this specific situation are questioned and the responses are translated into a final score. Although the MAS has been validated with many people from different countries such as Japan, Ethiopia, Turkey, France, and Spain, the scale has several limitations [19-22]. The scale predefines the type of disability (physical disability), and thus limits the extendibility of the scale to other types of disability. The scale also presets the respondent's relationship with the PWD (newly established personal contact), rendering it debatable whether the measured attitudes can be expanded to other relationships, such as attitudes toward public policies regarding unspecified general PWD or personal acquaintances with disabilities.

Atkinson and Hackett [23] suggested three viewpoints of attitudes toward PWD: burdensome, charitable, and egalitarian views. The burdensome view regards PWD as a burden to society. Since individuals with physical disabilities could not proportionately contribute to food gathering or other self-preservation campaigns, they were regarded as a burden to the community and were often left behind or sacrificed from the group. Such a view still prevails in modern society as forms of employment discrimination against PWD [24]. The charitable view, originating from the early years of Christian churches, deemed PWD as a charitable cause that warrants the provision of food, shelter, and social support. Such help was often in the form of segregated protection, such as asylums or hospitals. The sentiments accompanying conventional charitable views, such as pity, sympathy, and paternalism, continue to subsidize the PWD community [25]. However, the egalitarian view, developed relatively recently in the 1960s, demanded more civil rights for PWD, rather than requesting charity. Subsequently, a number of legislative acts were voted in including the
1990 Americans with Disabilities Act, the 1998 Crime Victims with Disabilities Awareness Act, and the 2001 No Child Left Behind Act [24,26].

Initially, we employed the three-subcategory structure in developing the preliminary items of APPD: cognition, affect, and behavior. However, after factor analysis, all behavioral domain items except one ("I will not let my children hang out with children with disabilities") were deleted. The cognition subdomain was divided further into two subcategories: community integration and sense of burdening. The affective subdomain was distinguished into discomfort and charitability. Two of these four new subdomains, sense of burdening and charitability, are comparable to Atkinson's burdensome and charitable viewpoints toward disability. Items from the community integration subdomain, such as, "persons with disabilities deserve to live where they want in ways they want" is similar to Atkinson's egalitarian viewpoint. Thus, we concluded that the factor analysis of the APPD found a new subdomain, "discomfort," to add to the existing Atkinson's three viewpoints.

Psychometric analysis of the APPD suggests that the final draft of APPD is a reliable and valid tool to assess social attitudes of non-healthcare professionals toward PWD. The item-subdomain correlation and internal consistency coefficients of each subdomain showed good internal consistency, and the confirmatory factor analysis showed that the model fit well, with adequate TLI and CFI.

The results of the APPD survey revealed that attitudes toward PWD differed between those who had close acquaintances with disabilities and those who did not. Their attitudes differed significantly as a whole, and in the subdomains of community integration and discomfort. This finding suggests that having personal relations with PWD has a significant impact on one's attitudes toward them.

Nevertheless, the subcategory of sense of burdening did not show any significant difference among any of the four groups surveyed. This finding reveals that, while stemming from the same Atkinsonian domain, cognition, discomfort and sense of burdening have different inherent cognitive traits. Specifically, items in discomfort are emotionally weighted and centered in the person answering ("I feel uncomfortable encountering PWD," "If I had a family member with disability, I would not want 
people to find out"), whereas items in sense of burdening are objective, third-person views on PWD as a population. Rather than asking about one's personal feelings when encountering an individual with disability, items of sense of burdening inquire if the respondent agrees that PWD as a group representation lays burden on society. Our study found that, while subjective emotions felt by those not accustomed to PWD are different from those who are, the views on PWD as a whole are more or less similar across all the groups.

The results does reveal that disability awareness education improves social attitudes toward PWD. Those who participated in the educational modules within 2 years showed more positive attitudes as a whole and in the subdomains of community integration, discomfort, and charitability. The significance was diluted when people who participated in disability awareness education more than 2 years ago were included as the educated group. This finding implies that although education is meaningful in promoting positive attitudes toward PWD, its effects are not permanent, and that regular sessions are warranted.

This study has some limitations. First, although the respondents were from various occupational and social backgrounds, they were employees of university hospitals. They included social workers, administrative staff, security staff, and volunteers. While their training and educational backgrounds vary, there may be a certain level of homogeneity among those who work in an environment where they are exposed to PWD regularly. Since APPD found that those with acquaintances with disabilities had more positive attitudes toward PWD, hospital employees who interact with PWD significantly more than the public may have more positive attitudes. Hospital workers as a group are a limited representation of the general public. This limitation warrants a further investigation using APPD in a more holistic representation of the real world population. In addition, this study was conducted in Korean. Although bilingual physicians and healthcare professionals translated the scales in English, validation may be required, especially in countries with diverse cultural backgrounds or medical environments. Finally, the test-retest reliability of the same person has not been investigated. The repeatability of APPD should be studied in future research.

The APPD scale is a newly developed tool that sensi- tively measures societal attitudes toward PWD. The scale is reliable, valid, short (14 items), and easy to score.

\section{CONFLICT OF INTEREST}

No potential conflict of interest relevant to this article was reported.

\section{ACKNOWLEDGMENTS}

The authors thank Eunhae Kim and Ye Il Kim at Seoul National University Hospital for their support as research assistants.

This work was supported by the Ministry of Education of the Republic of Korea and the National Research Foundation of Korea (No. NRD-2017S1A5A2A03068570).

\section{AUTHOR CONTRIBUTION}

Conceptualization: Shin HI, Yi YG. Methodology: Shin HI, Lee JE, Yi YG. Formal analysis: Myong Y, Cho WS, Yi YG. Funding acquisition: Shin HI, Yi YG. Project administration: Shin HI. Writing - original draft: Myong Y, Yi YG. Writing - review and editing: Myong Y, Shin HI, Cho WS, Yi YG. Approval of final manuscript: all authors.

\section{SUPPLEMENTARY MATERIALS}

Supplementary materials can be found via https://doi. org/10.5535/arm.21046.

\section{REFERENCES}

1. Antonak RF, Livneh H. Measurement of attitudes towards persons with disabilities. Disabil Rehabil 2000;22:211-24.

2. Mitchell KR, Hayes M, Gordon J, Wallis B. An investigation of the attitudes of medical students to physically disabled people. Med Educ 1984;18:21-3.

3. Peat M. Attitudes and access: advancing the rights of people with disabilities. CMAJ 1997;156:657-9.

4. Soder M. Prejudice or ambivalence? Attitudes toward persons with disabilities. Disabil Handicap Soc 1990;5:227-41.

5. Cheatham LP, Abell N, Kim H. Development and validation of the social worker's attitudes toward disabil- 
ity scale. J Soc Work Educ 2015;51:379-97.

6. Symons A, Fish R, McGuigan D, Fox J, Akl E. Development of an instrument to measure medical students' attitudes toward people with disabilities. Intellect Dev Disabil 2012;50:251-60.

7. Siller J, Ferguson L, Vann DH, Holland B. Structure of attitudes toward the physically disabled. New York, NY: New York University School of Education; 1967.

8. Block JR, Campbell WJ, Yuker HE. A scale to measure attitude toward disabled persons. Am Psychol 1959;14:351-2.

9. Antonak RF. Development and psychometric analysis of the Scale of Attitudes toward Disabled Persons. Durham, NH: University of New Hampshire; 1981.

10. Yuker HE, Block JR. Research with the Attitude Toward Disabled Persons scales (ATDP): 1960-1985. Hempstead, NY: Center for the Study of Attitudes Toward Persons with Disabilities, Hofstra University; 1986.

11. Gething L, Wheeler B. The Interaction with Disabled Persons Scale: a new Australian instrument to measure attitudes towards people with disabilities. Aust J Psychol 1992;44:75-82.

12. Findler L, Vilchinsky N, Werner S. The multidimensional attitudes scale toward persons with disabilities (MAS) construction and validation. Rehabil Couns Bull 2007;50:166-76.

13. Cowen EL, Underberg RP, Verrillo RT. The development and testing of an attitude to blindness scale. J Soc Psychol 1958;48:297-304.

14. Berkay PJ, Gardner JE, Smith PL. The development of the opinions about deaf people scale: a scale to measure hearing adults' beliefs about the capabilities of deaf adults. Educ Psychol Meas 1995;55:105-14.

15. Eagly AH, Chaiken S. The psychology of attitudes. Fort Worth, TX: Harcourt Brace Jovanovich College; 1993.

16. Chadd EH, Pangilinan PH. Disability attitudes in health care: a new scale instrument. Am J Phys Med
Rehabil 2011;90:47-54.

17. Tervo RC, Azuma S, Palmer G, Redinius P. Medical students' attitudes toward persons with disability: a comparative study. Arch Phys Med Rehabil 2002;83:1537-42.

18. Yuker HE, Hurley MK. Contact with and attitudes toward persons with disabilities: the measurement of intergroup contact. Rehabilitation Psychology 1987;32:145-54.

19. Dachez J, Ndobo A, Ameline A. French validation of the Multidimensional Attitude Scale toward Persons with Disabilities (MAS): the case of attitudes toward autism and their moderating factors. J Autism Dev Disord 2015;45:2508-18.

20. Stevens LF, Getachew MA, Perrin PB, Rivera D, Olivera Plaza SL, Arango-Lasprilla JC. Factor analysis of the Spanish Multidimensional Attitudes Scale toward Persons with Disabilities. Rehabil Psychol 2013;58:396404.

21. Tsujita M, Ban M, Kumagaya SI. The Japanese Multidimensional Attitudes Scale toward persons with autism spectrum disorders. Jpn Psychol Res 2021;63:12939.

22. Yelpaze I, Turkum AS. Adaptation and validation of Turkey version of multidimensional attitudes toward persons with disabilities. OPUS Uluslararası Toplum Araştırmaları Dergisi 2018;8:167-87.

23. Atkinson DR, Hackett G. Counseling diverse populations. Boston, MA: McGraw-Hill; 2004.

24. Gamst GC, Liang CT, Der-Karabetian A. Handbook of multicultural measures. Thousand Oaks, CA: Sage Publications; 2011.

25. Bowe FG. Handicapping America: barriers to disabled people. London, UK: Harper \& Row; 1978.

26. Stefan S. Unequal rights: discrimination against people with mental disabilities and the Americans with Disabilities Act. Washington, DC: American Psychological Association; 2001. 